\title{
CORRESPONDENCE
}

\section{Standardisation of breast tissue fixation procedures}

The Royal College of Pathologists Working Group have provided comprehensive guidelines for the reporting of histopathological specimens within the National Breast Screening Programme. ' We are concerned, however, that tissue fixation procedures are not to be standardised among participating laboratories.

Most fixatives penetrate tissues slowly; for example, $4 \%$ formaldehyde solution penetrates by $3.8 \mathrm{~mm}$ in 24 hours, ${ }^{23}$ so the centre of small unsliced breast biopsy specimens will not have been fixed within that period. The guidelines provide detailed instructions in relation to mastectomy specimens, but overnight fixation is sanctioned for unsliced breast biopsy specimens. ${ }^{1}$

We have recently shown that a delay in fixation of 24 hours produces a reduction in the number of observable mitotic figures in breast carcinomas of about $75 \% .{ }^{45}$ In some tumours the decreased count after just six hours can result in a change in the overall modified Bloom and Richardson tumour grade and hence prognostic group. ${ }^{5}$

These findings have important implications for the accuracy and validity of any multicentre study comparing breast carcinomas on the basis of a histological grading system that depends on the mitotic count. The inevitable variation in fixation delays of surgical specimens may be yet another factor which has contributed to the widely reported difficulties in consistency and reproducibility in breast carcinoma grading among centres. ${ }^{6}$

We believe that the failure to observe a defined system of tissue fixation may undermine any proposed pathological audit within the current National Breast Cancer Screening Programme.

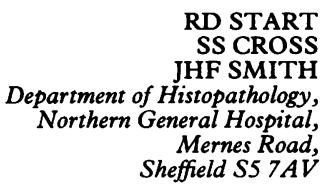

1 Royal College of Pathologists Working Group. Pathology reporting in breast cancer screening. J Clin Pathol 1990;44:710-25.

2 Medawar PB. The rate of penetration of fixatives. $J R$ Microsc Soc 1942;61:46-57.

3 Baker JR. Principles of biological microtechnique. London: Methuen, 1960:31-43.

4 Start RD, Flynn MS, Rogers K, Smith JHF. Delayed fixation significantly decreases observed mitotic figures in breast carcinoma. observed mitotic figures
$J$ Pathol 1991;163:154a.

5 Start RD, Flynn MS, Cross SS, Rogers K, Smith JHF. Is the grading of breast carcinoma Smith JHF. Is the grading of breast carcinoma
affected by a delay in fixation? Virchows Arch (Pathol Anat) (In press).

6 Elston CW. Grading of invasive carcinoma of the breast. In: Page DL, Anderson TJ. Diagnostic histopathology of the breast. Edinburgh: Churchill Livingstone, 1987:300-11.

On behalf of RLP Advisory Group on Quality Assurance in Breast Screening Dr Sloane et al comment :

We note with interest the comments made by Drs Start, Cross, and Smith on the procedure for fixing breast biopsy specimens recom- mended in the Pathology Guidelines for the National Breast Screening Programme.

We accept that in order to achieve uniformity of grading carcinomas specimens should ideally be sliced and immersed in fixative as soon as possible after excision. This may not only increase the number of mitotic figures but also the degree of morphological preservation. It may be impossible, however, for many pathologists to examine specimens within a short time of their removal with the consequent risk of leaving them unfixed for long periods. Incising and fixing them before thorough macroscopic inspection could lead to problems of subsequent orientation and interpretation, particularly if the incision is undertaken by the surgeon. In drawing up the Guidelines, the Working Group was very conscious of the need to strike a balance between the ideal and that which can practically be achieved. As most biopsy specimens from screened women are relatively small, we felt that recommending fixation in the intact state was acceptable and possibly safer than some of the possible alternatives.

Dr Start and colleagues report that delaying fixation of breast tumours reduces the observable number of mitoses and may change the modified Bloom and Richardson grade. As most of this work is still not published, we were obviously unable to take their observations into account when drawing up the Guidelines and are still not in a position to be able to evaluate in detail their relevance to the screening programme. A possible difficulty in this respect is that they have studied the effect of delaying the exposure of the tissue to fixative rather than comparing the effects of fixing intact or sliced specimens of specified size.

Although our Guidelines were published after extensive consultation, they were not intended to be sacrosanct but to be reviewed periodically in the light of experience and published data. We are about to begin such a review. We value the comments of Dr Start and colleagues and would be delighted to hear from anyone else who would like to express their views.

astric histamine concentration and IgE in Helicobacter pylori infection

Queiroz et al recently observed a significantly lower gastric histamine concentration in Helicobacter pylori positive patients than in $H$ pylori negative subjects and hypothesised that this might be due to increased histamine release with a subsequent depletion of stores. ${ }^{1}$

We evaluated the immune response involving IgE in patients with chronic gastritis who were infected with $H$ pylori. ${ }^{2}$ Of 26 patients with $H$ pylori infection, $22(84 \%)$ tested positive for basophil bound specific IgE (determined by the histamine release test) and $18(69 \%)$ for serum specific IgE (determined by an enzyme linked immunosorbent assay). In contrast, among 17 subjects in whom the bacterium was not detected, only one, with histologically confirmed gastritis, had cell bound and serum specific IgE. In four subjects who tested positive by the histamine release test without detectable specific circulating IgE, acid elution experiments showed that histamine release from basophils occurred as a result of an immunological mechanism. To demonstrate further the class specificity of the response, the $H$ pylori antigen was used to challenge normal basophils passively sensitised with serum from IgE positive patients. The significant histamine release obtained on exposure to antigen excluded interference with antibodies other than IgE directed against the same antigen. Inhibition experiments with bacteria other than $H$ pylori showed that the IgE antibody was specifically directed against this organism.

Our data strongly suggest that an immunological response involving $\mathrm{IgE}$ is present in patients infected with $H$ pylori. It is therefore conceivable that IgE has a role in inducing histamine release in the stomach through the activation of mast cells. In fact, these cells, which store histamine in human gastric mucosa, express specific surface receptors with high affinity for IgE. On antigenic stimulation mast cells are activated, undergo degranulation, and release their mediators by a secretory, energy requiring process. Not only histamine, but also other preformed or newly generated mediators released by mast cells, may be implicated in tissue damage.

The ability of $H$ pylori to induce a specific IgE immune response could answer key questions regarding the mechanisms of gastroduodenal inflammation.

$$
\begin{array}{r}
\text { A ACETI } \\
\text { D CELESTINO } \\
\text { M CAFERRO } \\
\text { A GRILLI } \\
\text { A PENNICA } \\
\text { O LERI } \\
\text { A SEBASTIANI } \\
\text { Institute of the Clinic of } \\
\text { Tropical and Infectious Diseases, } \\
\text { La Sapienza University, } \\
\text { 00161 Rome, Italy } \\
\text { V CASALE } \\
\text { F CITARDA } \\
\text { E M CONTI } \\
\text { A GRASSI } \\
\text { F SCIARRETTA } \\
\text { FAMEGLIO } \\
\text { Regina Elena, } \\
\text { Rome, Italy }
\end{array}
$$

1 Queiroz DMM, Mendes EN, Rocha GA, et al. Helicobacter pylori and gastric histamine Helicobacter pylori and gastric histamine
concentrations. J Clin Pathol 1991;44:612-3.

2 Aceti A, Celestino D, Caferro M. Basophilbound and serum immunoglobulin $E$ directed against Helicobacter pylori in patients with chronic gastritis. Gastroenterology 1991;101: 131-7.

Dr Queiroz comments:

We have shown that $H$ pylori positive patients, both children ${ }^{1}$ and adults, ${ }^{2}$ have lower gastric histamine concentrations than $H$ pylori negative subjects. This might be secondary to an increased release of histamine from mast cells which store histamine in human gastric mucosa; and induced by some $H$ pylori by-product; or by gastrin which is increased in $H$ pylori positive patients. ${ }^{3}$

Aceti et $a l^{4}$ have shown that there is an immunological response involving $\operatorname{IgE}$ in $H$ pylori positive patients and they have formulated the attractive hypothesis that in these patients specific IgE could have a role in gastric histamine release through activation of mast cells which express specific surface receptor for IgE. According to these authors, 
histamine as well as other mediators released after antigenic stimulation of the mast cell could be implicated in the development of tissue damage in $H$ pylori positive patients. We think that histamine released by these or by other mechanisms could also be involved in gastric acid hypersecretion in these patients.

1 Queiroz DMM, Mendes EN, Rocha GA, Barbosa AJA, Carvalho AST, Cunha-Melo JR. Histamine concentration of gastric mucosa in Helicobacter pylori positive and negative children. Gut 1991;32:464-6.

2 Queiroz DMM, Mendes EN, Rocha GA, et al. Helicobacter pylori and gastric histamine concentrations. J Clin Pathol 1991;44:612-3.

3 Smith JTL, Pounder RE, Nwokolo CU, et al. Inappropriate hypergastrinemia in asymptomatic healthy subjects infected with Helicobacter pylori. Gut 1990;31:522-5.

4 Aceti A, Celestino D, Caferro M, et al. Basophilbound and serum immunoglobulin E directed against Helicobacter pylori in patients with chronic gastritis. Gastroenterology 1991;101: 131-7.

\section{Repair of fetal bodies after dissection}

We have, for the past year, used a method similar to that described by Gau and her colleagues to repair both fresh and formalin fixed fetal bodies after dissection, ${ }^{1}$ and occasionally to completely reconstruct early second trimester fetuses received in fragments after genetic termination of pregnancy by suction or other evacuation methods. We have found that large skin defects in the small fetus can be repaired using a patch of amnion attached with adhesive. Whether a single or double layered patch of amnion or a sheet of amniochorial membrane is used depends on the fetal skin colour, thickness, and texture in the region to be repaired. Moreover, we have found that colourless cyano acrylate adhesive, usually referred to as Super glue and commonly used to assemble plastic models and for domestic repairs, is entirely satisfactory and fully acceptable to funeral directors and parents. Even in single drop dispensing tubes this is between 10 and 20 times cheaper than surgical adhesive and is cheaper still in larger tubes.

C MOTT HM CHAMBERS Department of Pathology, Department of Pathology,
Adelaide Medical Centre for Women and Children,
Queen Victoria Hospital, Adelaide, Australia

1 Gau GS, Napier K, Bhundia J. Use of a tissue adhesive to repair fetal bodies after dissection. $J$ Clin Pathol 1991;44:759-60.

\section{Experience of invasive aspergillosis in Hong Kong}

We read with interest the article by Boon et $a l^{1}$, and would like to share our experience in Hong Kong.

We reviewed the records of the 2462 necropsies performed between 1987 and 1990 by the Department of Pathology, Queen Mary Hospital, Hong Kong. Using the same criteria as Boon et al, ${ }^{1} 11$ cases of invasive aspergillosis were identified (eight males and three females with a mean age of 46.4 years, ranging from 12 to 81 years). Eight of these were considered to be high risk for aspergillosis: they had haematological malignancies (four with acute myeloid leukaemia, two with chronic myeloid leukaemia in blastic transformation, one with acute lymphoblastic leukaemia and one with polycythaemia rubra vera). One patient was receiving long term total parenteral nutrition after extensive gut surgery. Another was a 78 year old man with an incidental finding of a $1 \mathrm{~cm}$ hepatocellular carcinoma at necropsy. The last case was a 12 year old girl with apparent good health who suddently developed bronchopneumonia and died four days later; necropsy showed invasive aspergillosis in both lungs. The commonest site of infection is the lung, evident in all our cases, and other sites include the liver, spleen, kidneys and the heart.

Invasive aspergillosis was not diagnosed until necropsy in all our 11 cases, although fungal infection was strongly suspected in three of them. Repeated cultures for aspergillus were negative and transbronchial biopsy specimens were taken in the three cases, but none was considered diagnostic of aspergillosis.

Boon et al commented that invasive aspergillosis is not exclusive to the classic "high risk" group and included three in their report. ${ }^{1}$ There were also three such cases in our series, although two of the patients were debilitated by total parenteral nutrition or solid malignancy while the young girl was apparently healthy before death. Other authors have also reported similar experiences. ${ }^{23}$ While premortem diagnosis of invasive aspergillosis has been refined by new investigative techniques, ${ }^{4}$ it is still more often diagnosed at necropsy, ${ }^{1}$ and we reaffirm the value of necropsy in clinical audit. ${ }^{5}$

WH SHEK
KL CHAN
ISC LUK
Department of Pathology,
University of Hong Kong,
Queen Mary Hospital,
Hong Kong

1 Boon AP, O'Brien D, Adams DH. Ten year review of invasive aspergillosis detected at necropsy. J Clin Pathol 1991;44:452-4.

2 Hovenden JL, Nicklasson F, Barnes RA. Invasive pulmonary aspergillosis in immunocompromised patients. $B M J$ 1991;302:583-4.

3 Park GR, Drummond GB, Lamb D, et al. Disseminated aspergillosis occurring in patients with respiratory, renal and hepatic failure. Lancet 1982;ii:179-83.

4 Rogers TR, Haynes KA, Barnes RA. Value of antigen detection in predicting invasive pulantigen detection in predicting invasive pul-
monary aspergillosis. Lancet 1990;336: monary

5 Reid WA, Harkin PJR, Jack AS. Continual audit of clinical diagnostic accuracy by computer: a study of 592 autopsy cases. J Pathol 1987;153;99-107.

Costing of pathology services in the United Kingdom National Health Service

Professor Dick's useful review ended with a strong recommendation to pathologists to ensure they have "efficient resource management systems".' I cannot think how pathologists in the United Kingdom at present could disagree, but have a question and a comment.
The question is "who pays?"-that is, for the testing, introduction, and regular use of an efficient system.

The comment is that it is now vital that we pathologists give the same care and attention to obtaining and checking financial data about our laboratories, as most of us have for many years, to information about the number and variety of tests carried out and the quality of our results. In this department, however, the staff are very hard pressed to keep up with what, until now, has been regarded as their regular duties as clinical biochemists to provide results and comments to clinical colleagues, and it is hard to find the resources (staff) to assess, introduce, and apply simple computer packages for ordering, stock control, and noting expenditure without which accurate and precise budget statements can neither be obtained nor those from management validated.

A FLECK Charing Cross Hospital, Fulham Palace Road London W6 $8 R F$

1 Dick HM. Costing of pathology services in the United Kingdom National Health Service. J Clin Pathol 1991;44:705-9.

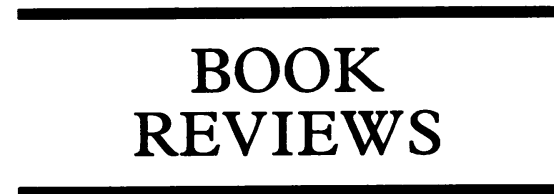

All titles reviewed here are available from the BMJ Bookshop, PO Box 295, London WC1H 9TE. Prices include postage in the United Kingdom and for members of the British Forces Overseas, but overseas customers should add $15 \%$ to the value of the order for postage and packing. Payment can be made by cheque in sterling drawn on a United Kingdom bank, or by credit card (Mastercard, Visa or American Express) stating card number, expiry date, and full name.

Surgical Pathology of the Female Reproductive System and Peritoneum. Ed SS Sternberg, SE Mills. (Pp 317; $\$ 102.00$ ). Raven Press. 1990. ISBN 0-88167726-4.

This short book, extracted from Diagnostic Surgical Pathology, covers the whole female genital tract, placenta, gestational trophoblastic disease and peritoneum in only eight chapters. It is not as detailed as the major diagnostic gynaecological text books, but the chapters are authoritative and comprehensively referenced up to 1990 . The text is clear with excellent monochrome and colour illustrations. Much of the content is familiar and represents a concise overview and updating of work presented in other textbooks. Hendrickson and Kempson's chapter on uterine pathology includes many of the charts and lists from their textbook. The three chapters which Young, Clement, and Scully have written on the ovary, fallopian tube, and peritoneum are excellent summaries and 